\title{
Effects of hydration status on cognitive performance and mood
}

\author{
Natalie A. Masento*, Mark Golightly, David T. Field, Laurie T. Butler and Carien M. van Reekum* \\ School of Psychology and Clinical Language Sciences, University of Reading, Whiteknights Campus, Earley Gate, \\ Whiteknights Road, Reading RGG 6AL, UK
}

(Submitted 24 June 2013 - Final revision received 17 December 2013 - Accepted 19 December 2013 - First published online 30 January 2014)

\section{Abstract}

Although it is well known that water is essential for human homeostasis and survival, only recently have we begun to understand its role in the maintenance of brain function. Herein, we integrate emerging evidence regarding the effects of both dehydration and additional acute water consumption on cognition and mood. Current findings in the field suggest that particular cognitive abilities and mood states are positively influenced by water consumption. The impact of dehydration on cognition and mood is particularly relevant for those with poor fluid regulation, such as the elderly and children. We critically review the most recent advances in both behavioural and neuroimaging studies of dehydration and link the findings to the known effects of water on hormonal, neurochemical and vascular functions in an attempt to suggest plausible mechanisms of action. We identify some methodological weaknesses, including inconsistent measurements in cognitive assessment and the lack of objective hydration state measurements as well as gaps in knowledge concerning mediating factors that may influence water intervention effects. Finally, we discuss how future research can best elucidate the role of water in the optimal maintenance of brain health and function.

\section{Key words: Hydration: Cognitive performance: Mood: Water consumption}

Growing evidence suggests that the food and drink that we consume affect mental and physical performance ${ }^{(1)}$. Food and food components that exhibit physiological and mental effects have been dubbed 'functional foods' or 'nutraceuticals' and are proposed as ways to help sustain good health and protect against illness, disease and pathological ageing ${ }^{(2)}$. Despite water constituting $60-80 \%$ of the human body, it is often overlooked as a significant nutrient that can affect not only physical performance, but also mental performance. In this review, we evaluate evidence from studies that investigated how cognitive performance is affected when water intake levels are low (i.e. during dehydration) or optimal and beyond (i.e. during acute water consumption). (To ensure that the review was comprehensive, we carried out literature searches using databases 'Web of Science' and 'Google Scholar' and obtained published studies that investigated dehydration and its effect on cognitive performance using search terms such as 'dehydration \& cognition', 'dehydration \& performance', and 'dehydration \& mental'. To obtain studies that investigated water consumption and how it influences cognitive performance, search terms such as the following were used: 'hydration \& cognition'; 'hydration \& performance'; 'hydration \& mental'; 'water consumption \& performance'; 'water consumption \& cognition'; 'drinking water \& cognition'.)
In addition to reviewing published research findings, we also discuss previously proposed mechanisms of action as well as new ones. Finally, based on the current state of the research area, we propose avenues for future investigations.

\section{Voluntary dehydration}

Evidence from public surveys ${ }^{(3,4)}$ and experimental investigations ${ }^{(5,6)}$ has indicated that the general public and particularly groups such as children and older adults are at a risk of voluntary dehydration ${ }^{(7,8)}$, such that individuals are drinking insufficient amounts of fluid resulting in sustained dehydration. Voluntary dehydration is likely to occur due to a lack of awareness of how much fluid consumption is required for a balanced hydration state (euhydration), especially when not taking into account the amount of daily activity; other external factors such as weather also contribute to this day-to-day variability in hydration requirements. Examples of voluntary dehydration have been reported in school children living in hot climates ${ }^{(5,6)}$ and also in a group of experienced runners who, although aware that they should rehydrate after exercise, drank insufficient amounts of water due to an underestimation of their hydration state, resulting in sustained dehydration ${ }^{(9)}$.

*Corresponding authors: N. A. Masento, email n.masento@pgr.reading.ac.uk; Dr C. M. van Reekum, fax +44 1183786715 ,

email c.vanreekum@reading.ac.uk 
Fluid balance within the body is maintained via homeostatic mechanisms ${ }^{(10)}$; water conservation occurs via the renal system, modifying urine production. Water intake is encouraged by thirst sensation. Although these mechanisms are intrinsic in homeostatic maintenance, they are also fallible, particularly in vulnerable groups such as children and older adults who maintain their hydration state inadequately. Inadequate hydration in young children and older adults may be due to dependency on carers, making self-motivation to seek fluid consumption difficult. There are also physiological issues of interpreting the thirst response, prompted by homeostatic mechanisms, which may be problematic due to inexperience in children ${ }^{(11,12)}$ and due to the deterioration of osmoreceptor sensitivity in older adults ${ }^{(13-15)}$. These factors preventing fluid consumption will over time result in individuals sustaining dehydration. Older adults are also more likely to have reduced kidney filtration function, resulting in less efficient water conservation when dehydrated, further exacerbating difficulties in recognising a dehydrated state ${ }^{(14)}$.

Sustained dehydration is associated with poor health ${ }^{(16,17)}$; chronic dehydration greatly increases the chances of kidney stones and urinary tract infection ${ }^{(16,18)}$, whereas prolonged vasoconstriction, as a result of chronic dehydration, can increase the chances of hypertension and stroke ${ }^{(10)}$. These physical consequences highlight the importance of preventing voluntary dehydration and make it a public health issue. Authoritative bodies such as the European Food Safety Authority (EFSA) support the scientific opinion that water contributes to the maintenance of normal physical and cognitive function ${ }^{(19)}$ and therefore have set recommended guidelines of $2000 \mathrm{ml}$ of fluids for females and $2500 \mathrm{ml}$ for males to be consumed per day ${ }^{(20)}$. These guidelines were set to encourage more fluid consumption and reduce the risk of sustained dehydration. There is some debate regarding the guidelines and the apparent lack of empirical evidence concerning the amount of additional fluids that individuals should actually consume ${ }^{(21,22)}$. Based on the high individual variability regarding fluid requirements, it is argued that the emphasis should be on encouraging individuals to monitor their own hydration levels using markers such as urine colour ${ }^{(23)}$ and to be aware of variables that may influence the amount of water they need to consume, such as climate and physical activity. To identify the best strategy for improving public water consumption, it is important to understand the factors that lead to the widespread neglect of water intake, as well as the impacts of inadequate water intake on both physical and mental performance.

\section{Dehydration and cognitive function}

Investigations into dehydration and mental performance were first systematically carried out in a military population ${ }^{(24)}$. Soldiers were exposed to extreme heat, inducing varying severities of dehydration. Cognitive abilities such as short-term memory, numerical ability, psychomotor function and sustained attention were assessed to establish any particular deficits as a result of changes in hydration status. Cognitive deficits were dependent on the severity of dehydration, which affected performance in all cognitive tasks when soldiers were in a severe state of dehydration ( $>2 \%$ body mass loss). This study was the first to emphasise that cognitive abilities were sensitive to a suboptimal hydration state.

Subsequent studies both in a military population and in the general population supported this initial evidence of detriments in cognitive abilities with induced dehydration ${ }^{(25-32)}$. However, relative to the study carried out by Gopinathan et $a{ }^{(24)}$, the cognitive deficits were more modest and only found in particular cognitive domains such as short-term memory and perceptual abilities, with preservation of other cognitive abilities such as working memory and executive function. Other studies ${ }^{(33-38)}$ found no support of cognitive impairment due to dehydration. These inconsistencies across empirical studies make it difficult to conclude whether, and how, dehydration affects cognitive performance (see Table 1 for all the dehydration and cognition function studies). Indeed, some experts have questioned where there is sufficient evidence to suggest that dehydration significantly affects cognitive performance ${ }^{(39)}$

Studies measuring self-reported changes in mental state have consistently found associations between dehydration and mood, in conjunction with changes in performance ${ }^{(27,30)}$ or with limited to no performance changes ${ }^{(35-37,40,41)}$. Despite variability in rating methods used, similar mood states were reported such as 'less alert', 'difficulty in concentrating', 'fatigue' and 'tension'(27,35,36,40-42). Some studies also reported that participants found completing the experimental tasks more difficult ${ }^{(35,36)}$ when in a dehydrated state. These findings highlight that self-reported mood states are sensitive to changes in hydration state and can occur independently from any cognitive performance changes.

One possible source of the heterogeneity in the profile of cognitive effects during dehydration may be the diversity in methods used to induce dehydration and to measure cognitive performance ${ }^{(43)}$. Early investigations used heat stress independently $^{(24)}$ as well as a combination of strenuous exercise and heat stress to create a severe dehydration state ${ }^{(25-27,35,40,44)}$, whereas more recent investigations have used fluid restriction to ascertain how mild dehydration influences performance $^{(32,36,45-47)}$. These methods vary in the degree of dehydration severity, which is probably a key determining factor of deficits in cognitive performance ${ }^{(24)}$. This is supported by recent mild dehydration investigations reviewed above, which found self-reported mood changes but the preservation of cognitive abilities ${ }^{(35,38,40)}$. The use of different methods also results in interpretive confounding factors. Specifically, evidence suggests that exercise alone improves cognitive performance ${ }^{(48)}$, which could counteract any potential deficit caused by dehydration. Increased core temperature via heat stress has also been shown to cause cognitive deficits, more so than dehydration ${ }^{(44)}$. Therefore, studies that use exercise and heat stress to induce dehydration may confound the mechanisms responsible for any effect found, placing into question whether these methods are optimal to investigate the influence of dehydration on cognitive performance.

Studies that have used fluid restriction to induce dehydration $^{(32,36,45-47)}$ are comparatively free of such 


\section{N British Journal of Nutrition}

Table 1. Characteristics of dehydration and cognitive function and/or mood studies

\begin{tabular}{|c|c|c|c|c|c|c|c|c|c|}
\hline Authors & $\begin{array}{l}\text { Sample } \\
\text { size }(n)\end{array}$ & Sample age & Design & Dehydration method & $\begin{array}{c}\text { Self-reported } \\
\text { measures }\end{array}$ & Other measures & Cognitive tasks & $\begin{array}{l}\text { Cognitive } \\
\text { performance/MRI change }\end{array}$ & $\begin{array}{l}\text { Self-reported } \\
\text { changes }\end{array}$ \\
\hline \multirow[t]{2}{*}{$\begin{array}{l}\text { Sharma } \\
\quad \text { et al. }{ }^{(49)}\end{array}$} & $8 \mathrm{men}$ & $\begin{array}{l}21-24 \text { years } \\
\text { old }\end{array}$ & $\begin{array}{l}\text { Repeated-measures } \\
\text { cross-over }\end{array}$ & Heat chamber with moderate activity & - & \%BMC & $\begin{array}{l}\text { Symbol substitution } \\
\text { test - processing speed }\end{array}$ & $\begin{array}{l}\text { Slower processing - } \\
\text { speed at } 3 \%\end{array}$ & - \\
\hline & & & & $\begin{array}{l}\text { Targeted varying severities of } \\
\text { dehydration }(1-3 \% \text { BMC) }\end{array}$ & & & $\begin{array}{l}\text { Concentration test - WM } \\
\text { Eye-hand coordination test - } \\
\text { psychomotor function }\end{array}$ & $\begin{array}{l}\text { Reduced psychomotor } \\
\text { function }\end{array}$ & \\
\hline \multirow[t]{2}{*}{$\begin{array}{l}\text { Gopinathan } \\
\text { et al. }\end{array}$} & 11 men & $\begin{array}{l}20-25 \text { years } \\
\text { old }\end{array}$ & $\begin{array}{l}\text { Repeated-measures } \\
\text { cross-over }\end{array}$ & $\begin{array}{l}\text { Heat chamber with moderate activity } \\
\text { Targeted varying severities of } \\
\text { dehydration }(1-4 \% \text { BMC) }\end{array}$ & - & \%BMC & $\begin{array}{l}\text { Word recognition - STM } \\
\text { Serial addition - } \\
\text { mathematical efficiency }\end{array}$ & $\begin{array}{l}\text { Global deficits at } 2 \%: \text { STM } \\
\text { Mathematical efficiency }\end{array}$ & - \\
\hline & & & & & & & $\begin{array}{l}\text { Trail-making test - } \\
\text { visuomotor processing }\end{array}$ & Visuomotor processing & \\
\hline \multirow[t]{5}{*}{ Cian et al..(.25) } & 8 men & $\begin{array}{l}\text { Mean age: } \\
27 \cdot 4 \\
\text { years }\end{array}$ & $\begin{array}{l}\text { Repeated-measures } \\
\text { cross-over }\end{array}$ & $\begin{array}{l}\text { Cond } 1 \text { : heat chamber - passive } \\
\text { hyperthermia to approximately } \\
2.8 \% \text { BMC }\end{array}$ & $\begin{array}{l}\text { VAS: fatigue and } \\
\text { mood }\end{array}$ & $\begin{array}{l}\text { \%BMC; heart rate; } \\
\text { blood samples; core } \\
\text { body temperature }\end{array}$ & $\begin{array}{l}\text { Pictures recall - long-term memory } \\
\text { task }\end{array}$ & $\begin{array}{l}\text { Slow perceptual } \\
\text { discrimination RT }\end{array}$ & $\begin{array}{r}\text { Increased } \\
\text { fatigue }\end{array}$ \\
\hline & & & & $\begin{array}{l}\text { Cond 2: } 60 \% \mathrm{VO}_{2 \max } \text { exercise to } \\
\text { approximately 2.8\% BMC }\end{array}$ & & & $\begin{array}{l}\text { Four-choice serial RT - visual } \\
\text { attention }\end{array}$ & Reduced STM recall & \\
\hline & & & & & & & $\begin{array}{l}\text { Perceptive discrimination - } \\
\text { perceptual processing }\end{array}$ & Psychomotor errors & \\
\hline & & & & & & & Digit span memory - STM & & \\
\hline & & & & & & & $\begin{array}{l}\text { Unstable tracking - } \\
\text { psychomotor skills }\end{array}$ & & \\
\hline \multirow[t]{2}{*}{ Cian et al. ${ }^{(26)}$} & 7 men & $\begin{array}{l}\text { Mean age: } \\
25 \text { years }\end{array}$ & $\begin{array}{l}\text { Repeated-measures } \\
\text { cross-over }\end{array}$ & $\begin{array}{l}\text { Cond } 1 \text { and } 2 \text { : heat chamber - } \\
\text { passive hyperthermia with or } \\
\text { without FR to approximately } \\
2.8 \% \mathrm{BMC}\end{array}$ & $\begin{array}{l}\text { VAS: fatigue and } \\
\text { mood }\end{array}$ & $\begin{array}{l}\text { \%BMC; heart rate; } \\
\text { core body } \\
\text { temperature }\end{array}$ & $\begin{array}{l}\text { Pictures recall - long-term } \\
\text { memory }\end{array}$ & Slower perceptual RT & $\begin{array}{l}\text { Increased } \\
\text { tiredness }\end{array}$ \\
\hline & & & & $\begin{array}{c}\text { Cond } 3 \text { and } 4: 65 \% \mathrm{VO}_{2 \max } \text { exercise } \\
\text { to approximately } 2.8 \% \mathrm{BMC}\end{array}$ & & & $\begin{array}{l}\text { Judgement of line length - } \\
\text { perceptual discrimination } \\
\text { RT - processing speed } \\
\text { Digit span test - STM } \\
\text { Unstable tracking - } \\
\text { psychomotor skills }\end{array}$ & $\begin{array}{l}\text { Impaired STM } \\
\text { performance }\end{array}$ & \\
\hline \multirow[t]{3}{*}{$\begin{array}{l}\text { Ainslie } \\
\quad \text { et al. }{ }^{(86)}\end{array}$} & $\begin{array}{l}17 \text { men: } \\
9 \text { younger }\end{array}$ & $\begin{array}{l}\text { Mean age: } \\
24 \text { years }\end{array}$ & $\begin{array}{l}\text { Independent sample } \\
- \text { YA }\end{array}$ & Exercise $-10 \mathrm{~d}$ walking activity & - & $\begin{array}{l}\text { Uosm; \%BMC; daily } \\
\text { dietary record; }\end{array}$ & Choice RT & $\begin{array}{l}\text { OA progressive dehy- } \\
\text { dration over } 10 \mathrm{ds}\end{array}$ & - \\
\hline & and 8 older & $\begin{array}{l}\text { Mean age: } \\
56 \text { years }\end{array}$ & v. OA & & & $\begin{array}{l}\text { energy expenditure; } \\
\text { blood samples }\end{array}$ & $\begin{array}{l}\text { Grip strength - motor } \\
\text { function }\end{array}$ & YA sustained euhydration & \\
\hline & & & & & & & $\begin{array}{l}\text { Flexibility and vertical } \\
\text { jump -muscle power }\end{array}$ & $\begin{array}{l}\text { Psychomotor function } \\
\text { deficit for } \mathrm{OA}\end{array}$ & \\
\hline Suhr et al. (46) & 28 adults & $\begin{array}{l}\text { Mean age: } \\
63 \cdot 7 \\
\text { years }\end{array}$ & Correlational & FR approximately $12 \mathrm{~h}$ & - & $\begin{array}{l}\text { \%BMC - bioelectrical } \\
\text { impedance }\end{array}$ & $\begin{array}{l}\text { RBANS - range of } \\
\text { cognitive abilities } \\
\text { Trail-making task - } \\
\text { psychomotor function } \\
\text { Grooved Pegboard } \\
\text { Test - manual dexterity }\end{array}$ & $\begin{array}{l}\text { Slower psychomotor } \\
\text { processing speed with } \\
\text { low \%BMC }\end{array}$ & - \\
\hline $\begin{array}{l}\text { Shirreffs } \\
\text { et al. }{ }^{(41)}\end{array}$ & 15 adults & $\begin{array}{l}\text { Mean age: } \\
30 \text { years }\end{array}$ & $\begin{array}{l}\text { Repeated-measures } \\
\text { cross-over }\end{array}$ & FR for $37 \mathrm{~h}$ & $\begin{array}{l}\text { VAS: thirst, mouth } \\
\text { dry, mouth } \\
\text { pleasant, } \\
\text { headache, } \\
\text { concentration, } \\
\text { tiredness and } \\
\text { alernness }\end{array}$ & $\begin{array}{l}\text { \%BMC; Uosm; blood } \\
\text { samples }\end{array}$ & - & - & $\begin{array}{l}\text { Increased } \\
\quad \text { headaches } \\
\text { Reduced } \\
\text { concentration } \\
\text { and alertness } \\
\text { at } 24 \text { and } \\
37 \mathrm{FR}\end{array}$ \\
\hline $\begin{array}{l}\text { Bar-David } \\
\quad \text { et al. }{ }^{(45)}\end{array}$ & 51 children & $\begin{array}{l}\text { Mean age: } \\
11 \text { years }\end{array}$ & $\begin{array}{l}\text { Independent } \\
\text { samples, } \\
>800 \text { mosm } / \mathrm{kg} \\
\mathrm{H}_{2} \mathrm{O} \text { (dehydrated) } \\
v .<800 \mathrm{mosm} / \mathrm{kg} \\
\mathrm{H}_{2} \mathrm{O} \text { (euhydrated) }\end{array}$ & $\begin{array}{l}\text { No intervention, natural hydration } \\
\text { state for comparison }\end{array}$ & - & Uosm & $\begin{array}{l}\text { Hidden figures - visual attention/ } \\
\text { perceptual speed } \\
\text { Auditory number span - WM } \\
\text { Making groups - semantic } \\
\text { flexibility } \\
\text { Verbal analogies - semantic } \\
\text { memory } \\
\text { Number addition - perceptual } \\
\text { speed and numerical reasoning }\end{array}$ & $\begin{array}{l}\text { Reduced STM at afternoon } \\
\text { testing for dehydrated } \\
\text { children }\end{array}$ & - \\
\hline
\end{tabular}


Table 1. Continued

\begin{tabular}{|c|c|c|c|c|c|c|c|c|c|}
\hline Authors & $\begin{array}{l}\text { Sample } \\
\text { size }(n)\end{array}$ & Sample age & Design & Dehydration method & $\begin{array}{l}\text { Self-reported } \\
\text { measures }\end{array}$ & Other measures & Cognitive tasks & $\begin{array}{l}\text { Cognitive } \\
\text { performance/MRI change }\end{array}$ & $\begin{array}{l}\text { Self-reported } \\
\text { changes }\end{array}$ \\
\hline $\begin{array}{l}\text { Szinnai } \\
\quad \text { et al. }{ }^{(36)}\end{array}$ & 16 adults & $\begin{array}{l}\text { Mean age: } \\
26 \text { years }\end{array}$ & $\begin{array}{l}\text { Repeated-measures } \\
\text { cross-over }\end{array}$ & FR for $28 \mathrm{~h}$ & $\begin{array}{l}\text { VAS: thirst, } \\
\text { effort and } \\
\text { concentration } \\
\text { Likert scale: } \\
\text { tiredness and } \\
\text { alertness }\end{array}$ & $\begin{array}{l}\text { Blood samples; Uosm; } \\
\text { auditory ERP }\end{array}$ & $\begin{array}{l}\text { Choice RT task - sustained visual } \\
\text { attention } \\
\text { Auditory serial addition task - } \\
\text { sustained/divided attention } \\
\text { Stroop task - verbal response time } \\
\text { Smooth pursuit rotor task - } \\
\text { manual tracking }\end{array}$ & No cognitive differences & $\begin{array}{l}\text { Increased } \\
\text { tiredness } \\
\text { Less alertness }\end{array}$ \\
\hline Petri et al. & $10 \mathrm{men}$ & $\begin{array}{l}\text { Mean age: } \\
25 \text { years }\end{array}$ & Repeated measures & FR for $24 \mathrm{~h}$ & $\begin{array}{l}\text { 10-point Likert } \\
\text { scale mood: } \\
\text { depression, } \\
\text { working } \\
\text { energy, } \\
\text { anxiety and } \\
\text { self-confidence }\end{array}$ & - & $\begin{array}{l}\text { Complex Reactionmeter Drenovac: } \\
\text { light signal position } \\
\text { discrimination } \\
\text { STM } \\
\text { Simple visual orientation } \\
\text { Simple arithmetic } \\
\text { Complex motor coordination }\end{array}$ & $\begin{array}{l}\text { Slower total solving time } \\
\text { found from } 9 \mathrm{~h} \text { of FR } \\
\text { and onwards }\end{array}$ & - \\
\hline Patel et al. (28) & 24 men & $\begin{array}{l}\text { Mean age: } \\
21.9 \\
\text { years }\end{array}$ & $\begin{array}{l}\text { Repeated-measures } \\
\text { cross-over }\end{array}$ & $\begin{array}{l}\text { FR for } 15 \mathrm{~h} \text { plus } 45 \min 65-70 \% \\
\mathrm{VO}_{2 \max } \text { exercise }\end{array}$ & $\begin{array}{l}\text { Concussion } \\
\text { measures } \\
\text { Sleep scale } \\
\text { test }- \text { fatigue } \\
\text { measure }\end{array}$ & $\begin{array}{l}\text { Balance error scoring } \\
\text { system } \\
\text { NeuroCom sensory } \\
\text { organisation test - } \\
\text { postural stability } \\
\text { USG }\end{array}$ & $\begin{array}{l}\text { ANAM } \\
\text { Simple RT } \\
\text { Mathematics processing test } \\
\text { Match-to-sample test } \\
\text { Sternberg memory test }\end{array}$ & $\begin{array}{l}\text { Reduced visual memory } \\
\text { performance }\end{array}$ & $\begin{array}{l}\text { Increased fatigue, } \\
\text { 'feeling slowed } \\
\text { down' and } \\
\text { 'difficulty } \\
\text { in concentrating' }\end{array}$ \\
\hline $\begin{array}{l}\text { Baker } \\
\quad \text { et al. }{ }^{(30)}\end{array}$ & 11 males & $\begin{array}{l}\text { Mean age: } \\
21 \cdot 3 \\
\text { years }\end{array}$ & Repeated measures & $\begin{array}{l}\text { Cond 1: exercise + placebo drink } \\
\text { Cond 2: exercise + carbohydrate } \\
\text { drink } \\
\text { Cond } 3-6 \text { : degrees of dehydration } \\
1-4 \%\end{array}$ & $\begin{array}{l}\text { VAS lightheaded- } \\
\text { ness, hotness } \\
\text { and total body } \\
\text { fatigue }\end{array}$ & $\begin{array}{l}\text { \%BMC; blood samples; } \\
\text { core body tempera- } \\
\text { ture }\end{array}$ & $\begin{array}{l}\text { Test of Variables in } \\
\text { Attention - continuous } \\
\text { performance test } \\
\text { Two versions: first half } \\
\text { frequent targets and second } \\
\text { half infrequent. }\end{array}$ & $\begin{array}{l}\text { Slower RT and increased } \\
\text { errors compared }\end{array}$ & $\begin{array}{l}\text { Increased fatigue, } \\
\text { lightheadedness } \\
\text { and overheating }\end{array}$ \\
\hline $\begin{array}{l}\text { Adam } \\
\quad \text { et al. }{ }^{(34)}\end{array}$ & 8 adults & $\begin{array}{l}\text { Mean age: } \\
24 \text { years }\end{array}$ & $\begin{array}{l}\text { Repeated-measures } \\
\text { cross-over }\end{array}$ & $\begin{array}{l}\text { Cond 1: exercise-induced } \\
\text { dehydration } \\
\text { Cond 2: passive heat dehydration } \\
\text { Cond 3: exercise plus fluids and } \\
\text { cold environment } \\
\text { Cond 4: exercise plus fluids and } \\
\text { temperate environment }\end{array}$ & $\begin{array}{l}\text { POMS; } \\
\text { NASA-TLX }\end{array}$ & $\% \mathrm{BMC}$ & $\begin{array}{l}\text { Sentry duty simulation - } \\
\text { marksmanship simulation with } \\
\text { weapon } \\
\text { Scanning visual vigilance }\end{array}$ & No cognitive differences & Not reported \\
\hline $\begin{array}{l}\text { Ackland } \\
\text { et al. }{ }^{(30)}\end{array}$ & 52 adults & $\begin{array}{l}\text { Mean age: } \\
62 \text { years }\end{array}$ & $\begin{array}{l}\text { Independent } \\
\text { measures: } \\
\text { colonoscopy } \\
\text { surgical patients } \\
\text { v. sigmoidoscopy } \\
\text { surgical patients }\end{array}$ & $\begin{array}{l}\text { Medical procedure - bowel } \\
\text { preparation }\end{array}$ & $\begin{array}{l}\text { Quality of } \\
\text { life - SF8 } \\
\text { Spielberger } \\
\text { State-Trait } \\
\text { Anxiety } \\
\text { Inventory } \\
\text { Subjective } \\
\text { cognition scale }\end{array}$ & $\begin{array}{l}\text { \%BMC - bioelectrical } \\
\text { impedance }\end{array}$ & $\begin{array}{l}\text { Trail-making test A and B } \\
\text { Rey Auditory Verbal Learning Test }\end{array}$ & No cognitive differences & $\begin{array}{l}\text { Colonoscopy } \\
\text { patients more } \\
\text { anxious }\end{array}$ \\
\hline $\begin{array}{l}\text { D'Anci } \\
\text { et al. } 27)\end{array}$ & $\begin{array}{l}54 \text { adults; } \\
\quad \text { study } \\
\text { 1: } 31 \text { adults }\end{array}$ & $\begin{array}{l}\text { Mean age: } \\
19.8 \\
\text { years }\end{array}$ & $\begin{array}{l}\text { Repeated-measures } \\
\text { cross-over }\end{array}$ & $\begin{array}{l}\text { Study } 1 \\
\text { Cond 1: } 60 \mathrm{~min} \text { exercise plus FR } \\
\text { Cond 2: } 60 \mathrm{~min} \text { exercise plus water }\end{array}$ & $\begin{array}{l}\text { Thirst sensation } \\
\text { scale; POMS }\end{array}$ & $\% \mathrm{BMC}$ & $\begin{array}{l}\text { Digit span forward task - STM } \\
\text { Simple RT } \\
\text { Choice RT } \\
\text { Kit of Factor-Referenced Cognitive } \\
\text { Test - map planning } \\
\text { Mathematical addition } \\
\text { Continuous performance task } \\
\text { Mental rotation task - visual } \\
\text { perception }\end{array}$ & $\begin{array}{l}\text { STM improvement } \\
\text { Decreased vigilance over } \\
\text { time }\end{array}$ & $\begin{array}{l}\text { Increased anger, } \\
\text { fatigue, } \\
\text { depression, } \\
\text { tension and } \\
\text { confusion }\end{array}$ \\
\hline
\end{tabular}



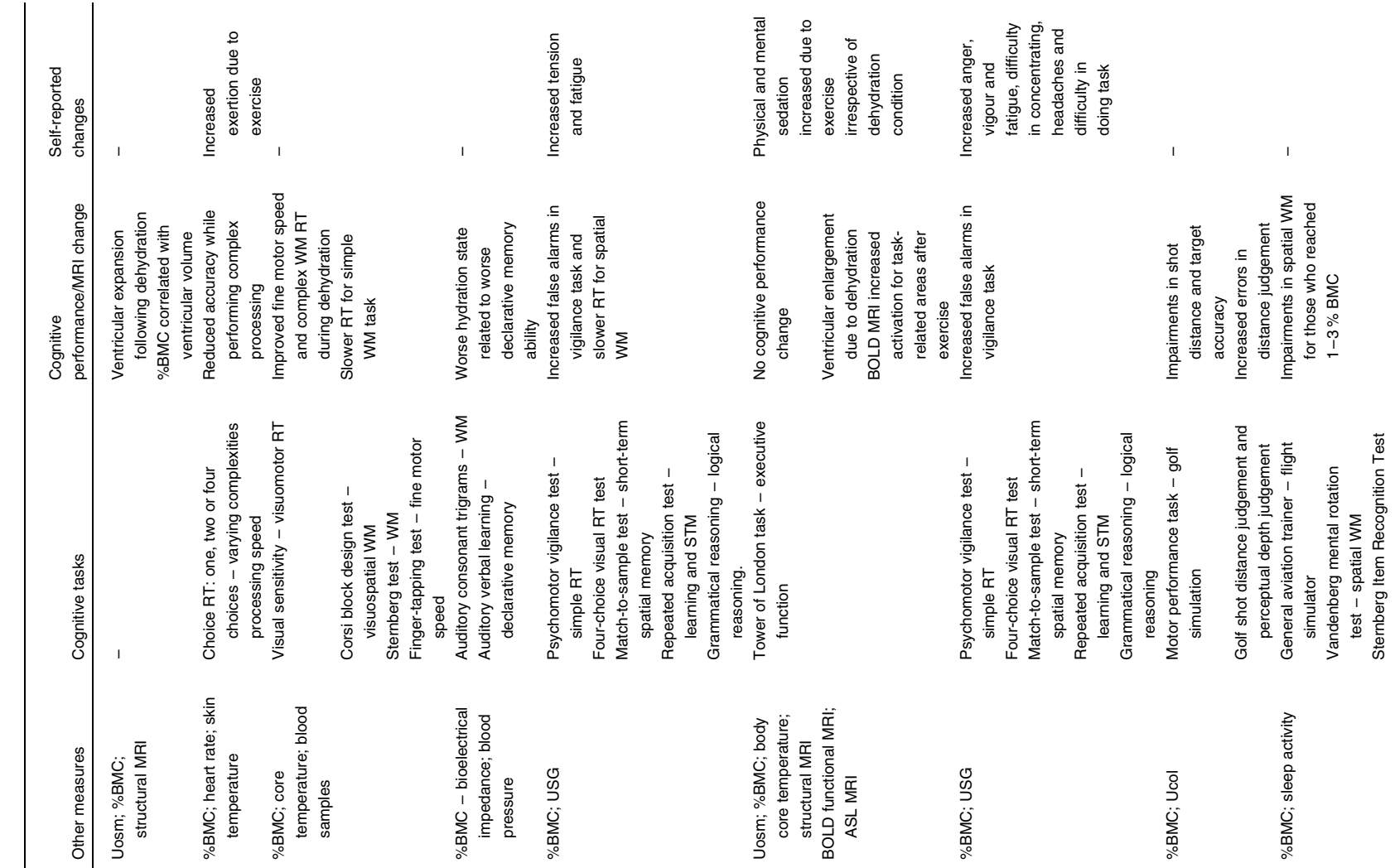

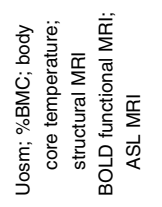

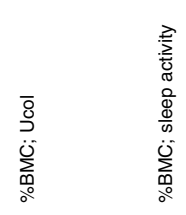

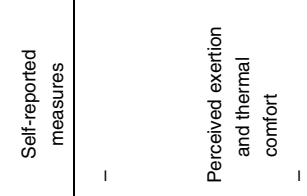
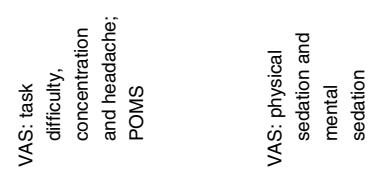

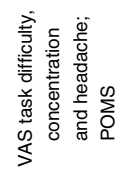
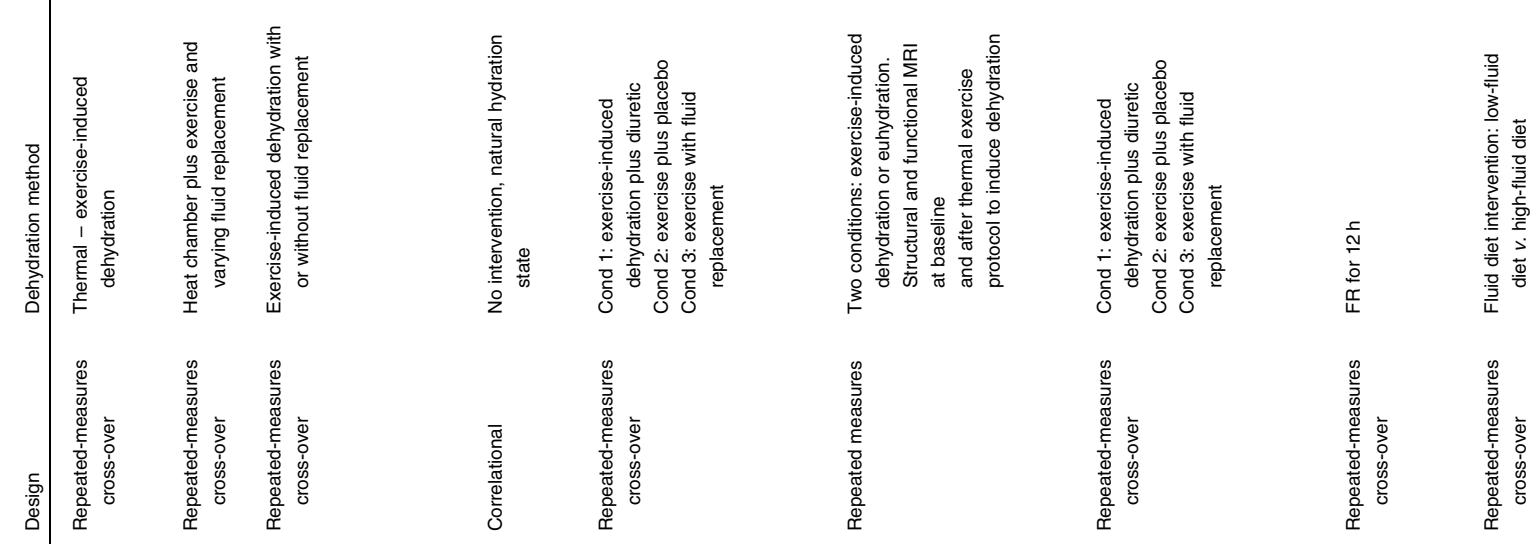

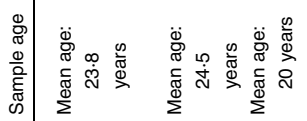

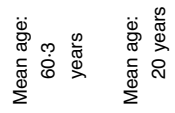
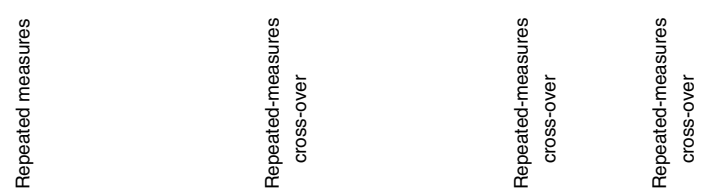

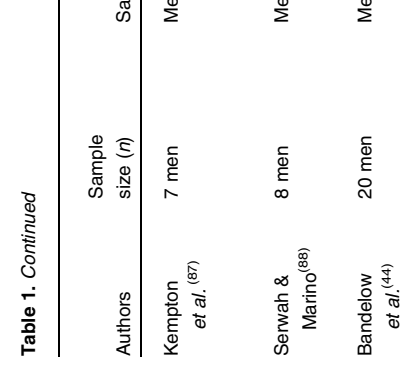
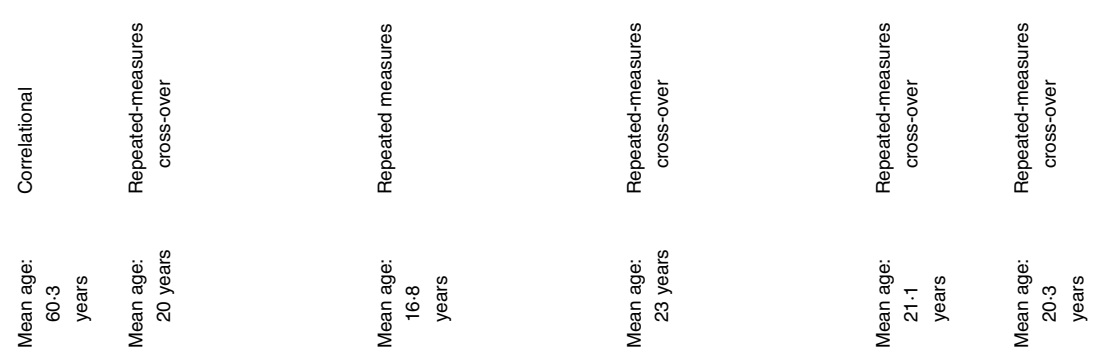

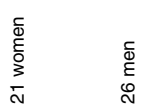

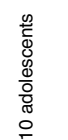

$\begin{array}{ll}\frac{\infty}{5} & \frac{\infty}{5} \\ \frac{5}{5} & \frac{\pi}{\pi} \\ \sim & \infty\end{array}$

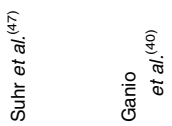

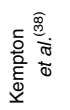

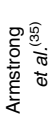

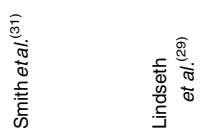


confounding factors. Interestingly, these studies tend to show modest cognitive deficits, if any, possibly reflecting that the participants were less severely dehydrated, although this is speculative; to date, no objective hydration state measure has been used to establish whether dehydration was induced. However, fluid restriction closely resembles routine voluntary dehydration behaviour found in the general population. Future research should focus on the extent to which fluid restriction may influence cognitive performance and ideally include objective measures of hydration state; this would not only advance the field of dehydration research but also benefit public health initiatives to encourage adequate fluid consumption.

As with any assessment of cognition, the tests chosen have a profound impact on the sensitivity to observe effects of the manipulation. There has been a propensity within the current collection of studies investigating dehydration and cognitive performance $^{(28,44,46,49)}$ to either use broad cognitive measurements from neuropsychological batteries or to select cognitive measurements based on previous use. These include batteries such as the Repeatable Battery for the Assessment of Neuropsychological Status and the Automated Neuropsychological Assessment Metrics. These neuropsychological tests often show little sensitivity to performance changes due to nutritional intervention, have inherently large variability in the detection of these performance differences and therefore lack validity in nutrition research. These issues with general neuropsychological tests that were not specifically designed for nutritional studies may lead to subtle effects being overlooked and an increase in false-negative reports. To avoid such issues, a number of researchers in this field, including Lieberman ${ }^{(43,50)}$ and Edmonds et al. ${ }^{(51,52)}$, have recommended that standardised cognitive measures, i.e. those that have previously shown sensitivity to nutritional interventions, should be utilised in future studies. Cognitive batteries that were designed for nutritional interventions such as phytochemicals have in recent years become popular ${ }^{(53)}$, and the identification of sensitive cognitive measurements in nutritional intervention contexts can be found in published reviews (see Macready et $\left.a l .{ }^{(54)}\right)$. Standardising the method of cognitive testing would also make it easier to corroborate evidence across different empirical studies in the future.

\section{Mechanisms of action}

Despite the inconsistent evidence of the impact of dehydration on cognitive performance, sustained dehydration is characterised by specific physiological changes. These physiological changes are part of a highly complex and variable system, making it particularly difficult to establish a unified baseline for hydration states across individuals. This issue perhaps underlies the variability in the findings of the influence of dehydration on cognition. Nevertheless, these physiological mechanisms of action may further inform us as to which aspects of mental performance are probably affected by dehydration. Reflecting on the homeostatic responses of dehydration, when the body is in a state of dehydration, many substrates and neurotransmitters are influenced by circulating vasopressin (also known as antidiuretic hormone) 
and angiotensin $\mathrm{II}^{(17,55)}$. These are key hormones involved in the homeostatic response of fluid imbalance ${ }^{(10)}$. One possible mechanism, proposed by researchers in this field ${ }^{(6,11,17)}$, for cognitive deficits during dehydration could be increased levels of cortisol, often released during a stress response. It has been shown that higher levels of cortisol can lower memory function and processing speed ${ }^{(56)}$ and consequently cause memory-related cognitive deficits ${ }^{(57)}$.

Other neurotransmitter systems have been shown to act differently as a consequence of dehydration, potentially mediating the cognitive deficits reported. Serotonergic and dopaminergic systems modify blood-brain barrier permeability, which, if sustained, causes central nervous system dysfunction $^{(58)}$. Findings also indicate that $\delta$-aminobutyric acid and glutamate levels increase during chronic dehydration, influencing both inhibitory and excitatory activities of the brain ${ }^{(59)}$. These modulations due to dehydration, however, are still unclear in relation to how they may influence functional brain activation and therefore cognitive performance. To better understand the mechanisms of action of dehydration on cognitive performance, studies directly manipulating dehydration and measuring the impact on neurotransmitter function should be carried out. For instance, positron emission tomography or magnetic resonance spectroscopy can be employed to uncover how the functioning of these neurotransmitter systems changes as a result of dehydration.

As described above, mild dehydration studies so far have failed to show a replicable impact on cognitive performance. Whether this is due to insufficiently sensitive cognitive measurements and issues of variability, discussed previously, or due to a genuine lack of impact of mild dehydration on cognitive performance remains unclear. The evidence for reported mood state changes is more consistent across studies. Despite the lack of behavioural changes in cognition, neural activity in brain regions involved in attention and executive function has been shown to increase when individuals are mildly dehydrated than when they are euhydrated ${ }^{(38)}$. One explanation is that individuals compensate for dehydration at both the neural and behavioural levels through investing greater effort and mental energy ${ }^{(60)}$, thus producing no net performance changes. Others suggest that NO production is increased during dehydration ${ }^{(61,62)}$. Indeed, studies have shown that NO production is associated with increased cerebral blood flow and vasodilation ${ }^{(63)}$ and could ultimately counteract any potential impairment to cognitive performance, leading to a sustained level of ability. These theorised processes need to be investigated further, focusing on the critical point at which the brain can no longer compensate for dehydration and at what point cognitive deficits begin.

\section{Acute water intervention and cognitive function}

With evidence to suggest that individuals are routinely at a risk of mild dehydration day to day ${ }^{(8)}$, particularly vulnerable populations such as children and older adults, there has been an increased interest in studying whether additional water consumption might benefit cognitive performance. The small collection of published water intervention studies involving either young adults or school children report consistent positive effects of water intervention on particular cognitive abilities.

\section{Acute water intervention and visual sustained attention}

Visual sustained attention has shown sensitivity to water consumption: the first study to investigate this ${ }^{(64)}$ employed a between-group design randomly allocating young adults to a no-water, $120 \mathrm{ml}$ water or $330 \mathrm{ml}$ water condition. Using a sustained attention task (rapid visual information-processing task), the participants were asked to locate target numbers among successive sequences. The researchers found a doserelated improvement in performance, with those in the $330 \mathrm{ml}$ water condition performing the best of the three groups and the no-water group performing the worst. However, this response was only found for those participants who reported thirst before the water intervention. These results suggest that visual sustained attention was sensitive to water consumption depending on the baseline hydration state of the individual. Interestingly, the task used in this study (rapid visual information processing) has not shown consistent results with acute water intervention. A subsequent study ${ }^{(65)}$ using a repeated-measures design and an overnight fast - the latter to minimise variability in baseline hydration - included this task and found no improvement in sustained attention or in other cognitive performance measures after a water intervention. The inconsistencies found between these two studies could be due to the differences in experimental design: Rogers et al. ${ }^{(64)}$ employed a between-group design, whereas Neave et al. ${ }^{(65)}$ used a within-subjects design controlling for baseline hydration state. Due to repeated exposure to the cognitive tasks, within-subjects designs are likely to suffer from practice effects, which can diminish the sensitivity of the cognitive measurements. As discussed above, insensitive cognitive assessments can increase false-negative reports and make it difficult to ascertain whether there is a genuine effect of water intervention. Further investigation is still needed to understand these inconsistencies and how the role of experimental design may interact with any influence that water consumption has on cognitive abilities.

Other water intervention studies have reported similar sustained attention performance changes without a dependency on prior thirst/hydration state. In a mixed design ${ }^{(66)}$, young adults were given $200 \mathrm{ml}$ of water and performance was found to increase from baseline in a sustained attention task (letter cancellation), which involved searching for a target letter within a grid. This was the only task to show improvement out of a battery of tasks including working memory assessments and simple reaction time. Other studies carried out by the same research group ${ }^{(67-69)}$ have replicated these improvements in visual sustained attention after water consumption in groups of school children. Despite these studies varying in the amounts of water ingested and experimental design, consistently these studies have shown visual sustained attention to improve after acute water consumption.

The corroborating evidence regarding visual sustained attention improvement after water intervention clearly 
highlights this as a key cognitive domain sensitive to water intervention. Further empirical studies should establish what particular component of this cognitive ability is benefiting from water intervention. One question that remains is whether attentional processes in other modalities such as auditory sustained attention would be similarly affected by acute water consumption. These recommendations have been made by researchers in the field ${ }^{(39,50,51,66)}$, but have thus far not been implemented in empirical research. Testing these different sensory modalities would help teasing apart whether water intervention improvement is specific to the visual system, as has been found in some flavonoid intervention studies, for example ${ }^{(70)}$, or whether higher-level, cross-modal attentional mechanisms are affected.

\section{Acute water intervention and short-term memory}

Short-term memory has also been shown to improve after water consumption. Short-term memory improvements after water consumption were found by three studies that investigated acute water intervention in school children ${ }^{(6,68,71)}$. The study carried out by Benton \& Burgess ${ }^{(71)}$ used a repeated-measures design with school children, assessing changes in the cognitive domains of short-term memory and sustained attention (using the recall of objects task and an auditory reaction time task). Interestingly, the authors failed to replicate water-induced performance improvements in the sustained attention task observed in other studies, possibly due to the task relying on auditory sustained attention rather than on visual sustained attention. However, the researchers did find that the children's short- and long-term recall of a list of objects improved after water consumption compared with no-water condition. A study carried out by Edmonds \& Burford ${ }^{(68)}$ testing 7-9-yearold children in London schools found that water consumption improved visual attention and visual memory. Using a 'spot the difference' task, the researchers found that water intervention significantly influenced children's visual memory: children who consumed water were able to identify more differences between two pictures compared with those who did not consume water. When taking into account the dosage of water consumed $(250 v$. $<250 \mathrm{ml})$, they also found that short-term memory performance was improved, but only for those who drank more water $(250 \mathrm{ml})$. The differential effect of dosage highlights that there may be a minimum amount of water consumption required to cause a significant impact on particular cognitive abilities and this no doubt will be related to the baseline hydration state of the children. Future studies should consider whether water dosage might have any differential effect on performance between various cognitive domains. Relatedly, a study that investigated Italian school children ${ }^{(6)}$ found that children who were less hydrated were more likely to perform worse in an auditory number memory task, also implying that optimal hydration leads to better performance in the auditory number memory task. This study further highlights the importance of including metrics of baseline hydration state of children, in this case urine osmolality, which is an objective hydration state measure. Inclusions of hydration state markers such as urine osmolality provide valuable information related to the day-to-day hydration levels of individuals and the extent to which these levels change after acute water consumption. Taking these measurements into account when assessing cognitive performance after water ingestion would contribute towards the understanding of the underlying mechanisms at work.

\section{Acute water intervention and simple reaction time}

A recent study carried out by Edmonds et al. ${ }^{(52)}$ has found improvements in simple reaction time after acute water intervention. The study consisted of thirty-three adults within a repeated-measures design. Cognitive performance changes were measured using the Cambridge Neuropsychological Test Automated Battery. When taking into account prior thirst of individuals, the researchers found that performance in the simple reaction time task was different between those who were thirsty and those who were not thirsty, with nonthirsty individuals exhibiting a relatively similar performance independent of water intake, whereas thirsty individuals performed significantly worse in the no-water condition. Even though thirst was measured subjectively, these results suggest that such subjective reports provide valuable information regarding hydration state; individuals who reported being thirsty during the experiment and were not provided with water supplementation were potentially mildly dehydrated, resulting in slower reaction times. This study helps us to understand how experienced variations in hydration state may interact with changes in cognitive performance. The majority of previous studies on this topic have lacked a measurement of baseline hydration status of their participants ${ }^{(52,64-69,71)}$, and with the findings from this study highlighting that thirst mediates the performance change in specific cognitive abilities, it is evident that we need to further our understanding of the relationship between hydration state and change in cognitive performance in future work.

\section{Acute water intervention and real-world settings}

The importance of an optimal hydration state for adequate cognitive performance has been highlighted by a range of studies reviewed above, all of which have been carried out within a laboratory setting testing individuals' performance using relatively controlled neuropsychological tasks that are impoverished in comparison with real-life demands. Therefore, it is important to test the effects of changing hydration states in real-world settings that require a complex array of cognitive abilities. Such studies have already been carried out, testing the effects of dehydration on performance in real-life tasks such as airplane piloting and playing golf ${ }^{(29,31)}$. An attempt has been made by one study to investigate how drinking-water may be related to performance in examinations in university students: Pawson et al. ${ }^{(72)}$ observed the number of people who took drinks to university examination sessions and compared the performance of these students with that of those who sat the same examination but did not take a drink. The results revealed a positive relationship between water taken to the examination session and 
performance in examination. Although these findings are correlational and do not include a measure of students' prior hydration state or of the amount of water consumed during the examination, these results support the notion that water consumption, or preventing dehydration, can have cognitive benefits. Further studies should investigate how drinking habits influence real-world settings, particularly for tasks that require a multitude of cognitive processes at once, such as driving and airline traffic control.

\section{Acute water intervention and mood}

Self-reported mood has been reported to show particular sensitivity to water consumption. One study that tested young adults on a range of cognitive tasks, including attention and working memory ${ }^{(65)}$, failed to find any significant impact of water consumption on cognitive performance. However, mood ratings were shown to significantly change when individuals were given water. Individuals reported feeling more 'calm' and 'alert' immediately after water consumption. These results are in line with those of other young adult studies that found similar reports of 'alertness' after water consumption ${ }^{(64)}$. The recent study carried out by Edmonds et al. ${ }^{(52)}$, which found that thirst mediated cognitive effects, also tested mood using visual analogue mood scales. The authors found that particular mood states were influenced by the counterbalanced order of water conditions. An example is that individuals were more confused when exposed to the control condition first, in which they did not receive any water, compared with when they were given water in the experimental condition. Interestingly, this relationship was moderated by drinking, indicating that water consumption was associated with lower reported confusion levels, irrespective of the condition order. This perhaps highlights that self-reported mood may be influenced by the expectancy of the experimental procedure itself and may have consequences for cognitive performance; therefore, it is important that participants are blind to the aims of the study to avoid such issues. Keeping participants blind in water intervention studies is particularly difficult when explicit instructions to consume water are provided. Considerations should be made to mask the true intentions of water consumption in such studies; one novel study was carried out by Edmonds et al. ${ }^{(66)}$, in which the experimenter had a drink her/himself and provided an additional cup of water without explicitly instructing the participants to consume the drink. The participants still consumed an adequate amount of water (approximately $167 \mathrm{ml}$ ) that was enough to exert a significant impact on cognitive performance.

The majority of studies that have investigated acute water intervention in children have either not included a mood measure or asked children to rate their 'happiness', which provides a measure of mood similar to standardised mood assessments, and yet have so far failed to show any change after water consumption. This is possibly because self-reported happiness may not be sensitive enough, particularly as happiness does not usually capture a state of arousal that has shown sensitivity to water intervention ${ }^{(64,65)}$. A more recent study involving children has used an adapted version of the Profiles of Mood State questionnaire designed for children ${ }^{(6)}$ and found a significant correlation between better hydration and reports of 'vigour', further supporting young adult mood reports. Studies that have included mood measures of alertness and other arousal states reveal that water consumption does have a significant impact on alertness and arousal; however, the extent to which this consumption sustains these mood changes is still inconclusive. Current findings suggest that these mood effects are short-lived and occur immediately after water consumption ${ }^{(64,65)}$. Future studies should consider investigating the temporal pattern of mood changes before and after water consumption.

\section{Mediating factors}

Despite only a relatively small collection of published empirical studies, evidence on acute water intervention hydration and cognition suggests that both cognitive performance and self-reported mood benefit from water consumption. As the field of water intervention is still in its infancy, there is some uncertainty as to how mediating factors such as water temperature and time of cognitive testing can influence subsequent intervention effects. To date, no water intervention studies have standardised water temperature and a majority of them have failed to report water temperature, despite evidence suggesting that particular chilled water temperatures $\left(5^{\circ} \mathrm{C}\right)$ are most pleasant and thirst quenching ${ }^{(73-75)}$. This may be a critical mediating factor, as individuals have shown preference for chilled water when deprived for a period of time ${ }^{(76)}$. This preference for chilled water may result in improved motivation and mood after consumption, more so than room temperature, potentially resulting in different outcomes due to water intervention.

Water temperature has also been shown to influence the rate of water absorption into the bloodstream from the gut ${ }^{(77)}$. This change in absorption could mediate the critical time at which cognitive performance measures should be taken. Based on the current evidence, water absorption in the gut reaches its peak into the bloodstream between 20 and $60 \mathrm{~min}$ after ingestion $^{(78,79)}$. Water intervention studies thus far have found cognitive performance changes within a critical window of $20-45 \min ^{(64,66,68,69,71)}$. This window is closely related to the peak absorption rates, suggesting that the critical time for cognitive testing should be in conjunction with this peak absorption point. Should water temperature vary, this peak absorption window is likely to be shifted and subsequently cognitive testing time would need to be altered. These are important considerations that need to be further investigated and considered in future empirical studies to truly identify how important these mediating factors are for water intervention effects.

\section{Mechanisms of action}

Despite the expansion of this research area, we still do not have a clear understanding as to how acute water intervention may influence mental performance and its associated neural activity. Researchers have suggested psychological mechanisms related to limited attentional resources during thirst ${ }^{(51,52,80)}$. However, evidence has also highlighted the importance of physiological 
mechanisms, with findings that the expectancy of water alone does not influence cognitive performance ${ }^{(66)}$. Herein, we not only discuss previously proposed mechanisms but also introduce new potential physiological mechanisms that we think have been previously overlooked.

Psychological mechanisms have been commonly proposed $^{(51,52,80)}$ to explain the effect of water consumption on cognitive abilities and mood states. The global workspace model $^{(81)}$ is a well-known generalised model of cognitive processes that postulates that there are limited amounts of cognitive resources and parallel processes often compete to obtain these resources. Applied to the topic at hand, states such as thirst and dehydration compete for these resources, resulting in limited capacity for other mental processes ${ }^{(80)}$. Within the context of acute water intervention, by alleviating the state of thirst and dehydration, these states no longer require allocation of resources, thus allowing parallel processes to recruit the required resources. This shift in cognitive resource allocation may provide the mechanism for performance change in cognitive tasks after water consumption. Support for this mechanism can be found in studies that demonstrated improvements in cognitive performance after hydration, with the level of thirst mediating the effect ${ }^{(52,64)}$. However, an alternative interpretation is that the state of thirst could be an indication of mild dehydration that could subsequently induce physiological changes, similar to those observed in brain imaging data ${ }^{(38)}$ such as total brain volume shrinkage. Future studies focusing on this potential mechanism will help us to decipher whether it is the influence of thirst itself or the consequence of dehydration that underlies any changes in cognitive performance.

Potential physiological mechanisms for performance improvements after water intervention are based on theorised physiological changes as a result of water consumption. To date, researchers have not explored these mechanisms. The importance of physiological mechanisms, in addition to psychological mechanism, is underscored by a recent study carried out by Edmonds et al. ${ }^{(66)}$. The researchers manipulated expectancy by informing half of the participants about the beneficial effects of water consumption on cognitive performance during either a no-water or water consumption period. Cognitive improvements were found after water intervention, with no influence of expectancy. The authors posit that these findings reveal the lack of influence that expectancy has on cognitive improvements after water intervention and provide support for physiological mechanisms. To date, it is still unclear as to what hydration state participants in empirical studies reviewed above actually experience. With a lack of objective measurement, it is not known whether individuals experience mild dehydration at baseline or a euhydrated state. With evidence to suggest that even mild dehydration states are associated with significant changes at the neural level, such as total brain volume shrinkage and over-recruitment of specific brain areas during cognitively demanding tasks ${ }^{(38)}$, it may be possible that providing mildly dehydrated participants with water may be reversing this effect. With a lack of data related to baseline hydration states of individuals and no further published work using imaging techniques to examine hydration state, these proposed mechanisms are merely speculative.

Another physiological mechanism to consider is the reactivity of the cardiovascular system after acute water consumption $^{(82)}$. Reduced heart rate and vasodilation have been found in young adults after drinking $500 \mathrm{ml}$ of water, whereas a significant blood pressure increase has been observed in healthy older adults ${ }^{(83)}$. This cardiovascular reactivity probably promotes cerebral blood flow, which will encourage the circulation of substances such as oxygen and glucose known to stimulate neural activity and associated behavioural performance $^{(84)}$, a mechanism similar to that suggested for cognitive function improvements due to physical exercise ${ }^{(85)}$. Future studies should consider using neuroimaging techniques such as functional MRI and perfusion to understand how cardiovascular changes can be related to neural activity changes and thus how these influence cognitive performance.

\section{Conclusion}

Accumulating evidence supports the notion that hydration state affects cognitive ability and mood. Severe dehydration has been shown to cause cognitive deficits such as short-term memory and visual perceptual abilities as well as mood disturbance, whereas water consumption can improve cognitive performance, particularly visual attention and mood. This research field is still in its infancy and fundamentally there is still a high amount of variability with regard to cognitive findings in both dehydration and acute water intervention studies. Researchers should investigate why this variability occurs and what the optimum conditions are for hydration state to affect cognitive performance. In this review, we have highlighted the importance of controlling for any potential confounding factors that may occur due to experimental design, exercise/heat stress protocols used in dehydration studies or conditions related to acute water intervention such as water temperature. Other advancements include taking into account the mechanisms that may underlie the observed performance changes: conducting behavioural studies with physiological markers to monitor hydration state such as urine indices and neuroimaging studies to discover the underlying neural events during hydration state change. Standardising cognitive testing would also help advance knowledge in this field. The topic is highly relevant for public health and engages with a wide audience, and this research has the potential to pave the way for intervention programmes in public arenas, improving people's quality of life.

\section{Acknowledgements}

The authors thank Professor David Richardson for his assistance in the preparation of the final manuscript.

Britvic Soft Drinks Plc (grant number: F3408400) partially funded the PhD studentship of N. A. M. Britvic Soft Drinks had no role in the design and analysis or writing of this article.

All authors contributed to the manuscript equally.

None of the authors has any conflicts of interest to declare. 


\section{References}

1. Gomez-Pinilla F (2008) Brain foods: the effects of nutrients on brain function. Nat Rev Neurosci 9, 568-578.

2. Dye L \& Blundell J (2007) Functional foods: psychological and behavioural functions. BrJ Nutr 88, Suppl. 2, S187-S211.

3. Gandy J (2012) First findings of the United Kingdom fluid intake study. Nutr Today 47, S14-S16.

4. Gibson S, Gunn P \& Maughan RJ (2012) Hydration, water intake and beverage consumption habits among adults. Nutr Bull 37, 182-192.

5. Bar-David Y, Urkin J, Bar-David Z, et al. (2009) Voluntary dehydration among elementary school children residing in a hot arid environment. J Hum Nutr Diet 22, 455-460.

6. Fadda R, Rapinett G, Grathwohl D, et al. (2012) Effects of drinking supplementary water at school on cognitive performance in children. Appetite 59, 730-737.

7. Greenleaf JE (1992) Problem: thirst, drinking behavior, and involuntary dehydration. Med Sci Sports Exerc 24, 645-656.

8. Greenleaf JE \& Sargent F (1965) Voluntary dehydration in man. J Appl Physiol 20, 719-724.

9. Passe D, Horn M, Stofan J, et al. (2007) Voluntary dehydration in runners despite favorable conditions for fluid intake. Int J Sport Nutr Exerc Metab 17, 284-295.

10. Thornton SN (2010) Thirst and hydration: physiology and consequences of dysfunction. Physiol Behav 100, 15-21.

11. D'Anci K, Constant F \& Rosenberg I (2006) Hydration and cognitive function in children. Nutr Rev 64, 457-464.

12. Kenney WL \& Chiu P (2001) Influence of age on thirst and fluid intake. Med Sci Sports Exerc 33, 1524-1532.

13. Begum MN \& Johnson CS (2010) A review of the literature on dehydration in institutionalized elderly. e-Spen Eur e-J Clin Nutr Metab 5, e47-e53.

14. Mentes J (2006) Oral hydration in older adults: greater awareness is needed in preventing, recognizing, and treating dehydration. Am J Nurs 106, 40-49.

15. Rolls BJ \& Phillips PA (2009) Aging and disturbances of thirst and fluid balance. Nutr Rev 48, 137-144.

16. Popkin B, D'Anci K \& Rosenberg I (2010) Water, hydration and health. Nutr Rev 68, 439-458.

17. Wilson MM \& Morley JE (2003) Impaired cognitive function and mental performance in mild dehydration. Eur J Clin Nutr 57, S24-S29.

18. Jequier E \& Constant F (2010) Water as an essential nutrient: the physiological basis of hydration. Eur J Clin Nutr 64, 115-123.

19. EFSA (2011) Scientific opinion on the substantiation of health claims related to water and maintenance of normal physical and cognitive functions (ID 1102, 1294, 1331), maintenance of normal thermoregulation (ID 1208) and "basic requirement of all living things" (ID 1207) pursuant to Article 13(1) of Regulation (EC) No. 1924/2006. EFSA J 9, 2075.

20. EFSA (2010) Scientific opinion on dietary reference values for water: EFSA panel on dietetic products, nutrition, and allergies (NDA). EFSA J 8, 1459 .

21. Cohen D (2012) The truth about sports drinks. Br Med J 345 , e4737.

22. Valtin H (2002) Drink at least eight glasses of water a day. Really? Is there scientific evidence for " $8 \times 8$ "? Am J Physiol Regul Integr Comp Physiol 283, R993-R1004.

23. Armstrong LE (2005) Hydration assessment techniques. Nutr Rev 63, S40-S54.

24. Gopinathan PM, Pichan G \& Sharma V (1988) Role of dehydration in heat stress-induced variations in mental performance. Arch Environ Heal 43, 15-17.

25. Cian C, Koulmann N, Barraud P, et al. (2000) Influence of variations in body hydration on cognitive function: effect of hyperhydration, heat stress, and exercise-induced dehydration. J Psychophysiol 14, 29-36.

26. Cian C, Barraud P, Melin B, et al. (2001) Effects of fluid ingestion on cognitive function after heat stress or exerciseinduced dehydration. Int J Psychophysiol 42, 243-251.

27. D'Anci K, Vibhakar A, Kanter JH, et al. (2009) Voluntary dehydration and cognitive performance in trained college athletes. Percept Mot Skills 109, 251-269.

28. Patel AV, Mihalik JP, Notebaert AJ, et al. (2007) Neuropsychological performance, postural stability, and symptoms after dehydration. J Athl Train 42, 66-75.

29. Lindseth P, Lindseth G, Petros T, et al. (2013) Effects of hydration on cognitive function of pilots. Mil Med 178, 792-798.

30. Baker LB, Conroy DE \& Kenney WL (2007) Dehydration impairs vigilance-related attention in male basketball players. Med Sci Sports Exerc 39, 976-983.

31. Smith MF, Newell AJ \& Baker MR (2012) Effect of acute mild dehydration on cognitive-motor performance in golf J Strength Cond Res 26, 3075-3080.

32. Petri NM, Dropulic N \& Kardum G (2006) Effects of voluntary fluid intake deprivation on mental and psychomotor performance. Croat Med J 47, 855-861.

33. Ackland GL, Harrington J, Downie P, et al. (2008) Dehydration induced by bowel preparation in older adults does not result in cognitive dysfunction. Anesth Analg 106, 924-929.

34. Adam GE, Carter R III, Cheuvront S, et al. (2008) Hydration effects on cognitive performance during military tasks in temperature and cold environments. Physiol Behav 93, $748-756$

35. Armstrong LE, Ganio MS, Casa DJ, et al. (2012) Mild dehydration affects mood in healthy young women. $J$ Nutr $\mathbf{1 4 2}$, 382-388.

36. Szinnai G (2005) Effect of water deprivation on cognitivemotor performance in healthy men and women. $A m J$ Physiol Regul Integr Comp Physiol 289, R275-R280.

37. Ely BR, Sollanek KJ, Cheuvront SN, et al. (2012) Hypohydration and acute thermal stress affect mood state but not cognition or dynamic postural balance. Eur J Appl Physiol 113, 1027-1034.

38. Kempton MJ, Ettinger U, Foster R, et al. (2011) Dehydration affects brain structure and function in healthy adolescents. Hum Brain Mapp 32, 71-79.

39. Benton D (2011) Dehydration influences mood and cognition: a plausible hypothesis? Nutrients 3, 555-573.

40. Ganio MS, Armstrong LE, Casa DJ, et al. (2011) Mild dehydration impairs cognitive performance and mood of men. Br J Nutr 106, 1535-1543.

41. Shirreffs SM, Merson SJ, Fraser SM, et al. (2004) The effects of fluid restriction on hydration status and subjective feelings in man. BrJ Nutr 91, 951-958.

42. Pross N, Demazières A, Girard N, et al. (2012) Influence of progressive fluid restriction on mood and physiological markers of dehydration in women. BrJ Nutr 109, 313-321.

43. Lieberman HR (2007) Hydration and cognition: a critical review and recommendations for future research. $J \mathrm{Am}$ Coll Nutr 26, 555s-561s.

44. Bandelow S, Maughan RJ, Shirreffs SM, et al. (2010) The effects of exercise, heat, cooling and rehydration strategies on cognitive function in football players. Scand J Med Sci Sports 20, Suppl. 3, 148-160.

45. Bar-David Y, Urkin J \& Kozminsky E (2005) The effect of voluntary dehydration on cognitive function of elementary school children. Acta Paediatr 94, 1667-1673.

46. Suhr J, Hall J, Patterson SM, et al. (2004) The relation of hydration status to cognitive performance in healthy older adults. Int J Psychophysiol 53, 121-125. 
47. Suhr JA, Patterson SM, Austin AW, et al. (2010) The relation of hydration status to declarative memory and working memory in older adults. J Nutr Health Aging 14, $840-843$

48. Tomporowski P \& Ellis NR (1986) Effects of exercise on cognitive processes: a review. Psychol Bull 99, 338-346.

49. Sharma VM, Sridharan K, Pichan G, et al. (1986) Influence of heat-stress induced dehydration on mental functions. Ergonomics 29, 791-799.

50. Lieberman HR (2012) Methods for assessing the effects of dehydration on cognitive function. Nutr Rev 70, S143-S146.

51. Edmonds C (2012) Water, hydration state and cognitive performance. In Nutrition and Mental Performance, pp. 193-212 [LM Riby, M Smith and J Foster, editors]. London: Palgrave Macmillan.

52. Edmonds CJ, Crombie R \& Gardner MR (2013) Subjective thirst moderates changes in speed of responding associated with water consumption. Front Hum Neurosci 7, 363.

53. Kennedy DO \& Haskell CF (2011) Cerebral blood flow and behavioural effects of caffeine in habitual and non-habitual consumers of caffeine: a near infrared spectroscopy study. Biol Psychol 86, 298-306.

54. Macready AL, Butler LT, Kennedy OB, et al. (2010) Cognitive tests used in chronic adult human randomised controlled trial micronutrient and phytochemical intervention studies. Nutr Res Rev 23, 200-229.

55. Bourque CW (2008) Central mechanisms of osmosensation and systemic osmoregulation. Nat Rev Neurosci 9, 519-531.

56. Comijs HS, Gerritsen L \& Penninx WJH (2010) The association between serum cortisol and cognitive decline in older adults. Am J Geriatr Psychiatry 18, 42-50.

57. Raber J (1998) Detrimental effects of chronic hypothalamic pituitary adrenal axis activation. Mol Neurobiol 18, 1-22.

58. Maughan R, Shirreffs S \& Watson P (2007) Exercise, heat, hydration and the brain. J Am Coll Nutr 26, 604S-612S.

59. Di S \& Tasker J (2004) Dehydration-induced synaptic plasticity in magnocellular neurons of the hypothalamus supraoptic nucleus. Endocrinology 145, 5141-5149.

60. Gorby HE, Brownawell AM \& Falk MC (2010) Do specific dietary constituents and supplements affect mental energy? Review of the evidence. Nutr Rev 68, 697-718.

61. Kadekaro M, Su G, Chu R, et al. (2006) Nitric oxide upregulates the expression of calcium-dependent potassium channels in the supraoptic nuclei and neural lobe of rats following dehydration. Neurosci Lett 404, 50-55.

62. Ueta Y, Levy A, Chowdrey H, et al. (1995) Water deprivation in the rat induces nitric oxide synthase (NOS) gene expression in the hypothalamic paraventricular and supraoptic nuclei. Neurosci Res 23, 317-319.

63. Toda N \& Okamura T (2010) Modulation of renal blood flow and vascular tone by neuronal nitric oxide synthase-derived nitric oxide. J Vasc Res $\mathbf{4 8}, 1-10$.

64. Rogers PJ, Kainth A \& Smit HJ (2001) A drink of water can improve or impair mental performance depending on small differences in thirst. Appetite 36, 57-58.

65. Neave N, Scholey AB, Emmett JR, et al. (2001) Water ingestion improves subjective alertness, but has no effect on cognitive performance in dehydrated healthy young volunteers. Appetite 37, 255-256.

66. Edmonds CJ, Crombie R, Ballieux H, et al. (2013) Water consumption, not expectancies about water consumption, affects cognitive performance in adults. Appetite $\mathbf{6 0}$ 148-153.

67. Booth P, Taylor B \& Edmonds C (2012) Water supplementation improves visual attention and fine motor skills in school children. Educ Health 30, 75-79.
68. Edmonds C \& Burford D (2009) Should children drink more water? The effects of drinking water on cognition in children. Appetite 52, 776-779.

69. Edmonds C \& Jeffes B (2009) Does having a drink help you think? 6-7 year old children show improvements in cognitive performance from baseline to test after having a drink of water. Appetite 53, 469-472.

70. Field DT, Williams CM \& Butler LT (2011) Consumption of cocoa flavanols results in an acute improvement in visual and cognitive function. Physiol Behav 103, 255-260.

71. Benton D \& Burgess N (2009) The effect of the consumption of water on the memory and attention of children. Appetite 53, 143-146.

72. Pawson C, Gardner MR, Doherty S, et al. (2013) Drink availability is associated with enhanced examination performance in adults. Psychol Teach Rev 19, 57-67.

73. Brunstrom J \& Macrae A (1997) Effects of temperature and volume on measures of mouth dryness, thirst and stomach fullness in males and females. Appetite 29, 31-42.

74. Labbe D, Martin N, Le Coutre J, et al. (2011) Impact of refreshing perception on mood, cognitive performance and brain oscillations: an exploratory study. Food Qual Prefer 22, 92-100.

75. Saltmarsh M (2001) Thirst: or, why do people drink? Nutr Bull 26, 53-58.

76. Labbe D, Almiron-Roig E, Hudry J, et al. (2009) Sensory basis of refreshing perception: role of psychophysiological factors and food experience. Physiol Behav 98, 1-9.

77. Bateman DN (1982) Effects of meal temperature and volume on the emptying of liquid from the human stomach.J Physiol 331, 461-467.

78. Lambert CP, Ball D, Leiper JB, et al. (1999) The use of deuterium tracer technique to follow the fate of fluids ingested by human subjects: effects of drink volume and tracer concentration and content. Exp Physiol 84, 391-399.

79. Péronnet F, Mignault D, du Souich P, et al. (2012) Pharmacokinetic analysis of absorption, distribution and disappearance of ingested water labeled with $\mathrm{D}_{2} \mathrm{O}$ in humans. Eur J Appl Physiol 112, 2213-2222.

80. Cohen S (1983) After effects of stress on human performance during a heat acclimatization regimen. Aviat Space Environ Med 54, 709-713.

81. Baars B (1993) How does a serial, integrated and very limited stream of consciousness emerge from a nervous system that is mostly unconscious, distributed, parallel and of enormous capacity? Ciba Found Symp 174, 282-290.

82. May M \& Jordan J (2011) The osmopressor response to water drinking. Am J Physiol Regul Integr Comp Physiol 300, R40-R46.

83. Schroeder C, Bush VE, Norcliffe LJ, et al. (2002) Water drinking acutely improves orthostatic tolerance in healthy subjects. Circulation 106, 2806-2811.

84. Gold PE (1995) Role of glucose in regulating the brain and cognition. Am J Clin Nutr 61, 987S-995S.

85. Kashihara K, Maruyama T, Murota M, et al. (2009) Positive effects of acute and moderate physical exercise on cognitive function. J Physiol Anthropol 28, 155-164.

86. Ainslie PN, Campbell IT, Frayn KN, et al. (2012) Energy balance, metabolism, hydration, and performance during strenuous hill walking: the effect of age. J Appl Physiol 93, 714-723.

87. Kempton MJ, Ettinger U, Schmechtig A, et al. (2009) Effects of acute dehydration on brain morphology in healthy humans. Hum Brain Mapp 30, 291-298.

88. Serwah N \& Marino FE (2006) The combined effects of hydration and exercise heat stress on choice reaction time. J Sci Med Sport 9, 157-164. 